\title{
HARDNESS TESTING.
}

(BY MEANS OF TWO NEW TYPES OF MACHINES.)

By H. S. PRimRose, of Braintree, and J. S. Glen PRIMrose, on Ipswich, Associates.

[Selected for Publication.]

General Principle of Load Calibrating Box.-On a former occasion the Authors, in their Paper on "Some Useful Testing Machines," read before the West of Scotland Iron and Steel Institute and the South Staffordshire Iron and Steel Institute, described a new form of standardizing box for calibrating testing machines in tension or compression stresses. The principle of this instrument is that, when subjected to a tension or compression load, it is deformed in a degree proportional to the stress applied, and the volume change of the box gives a very accurate measurement of the load applied by means of a micrometer reading. The readings are also invariable for each box of the three different sizes made.

The standardizing boxes are constructed in the form of thinwalled, hollow cylinders made of special steel which has been suitably heat-treated, so that, even whon highly stressed, they do not suffer any permanent deformation. The interior of the box is filled with mercury (A), Fig. 1, Plate 14, and the fullness of the cavity is indicated by the level of the column of mercury extending into the capillary glass tube (B), mounted in the side of the instrument. On this tube is a sliding mark (C) to which the level of the mercury column is always brought back by turning the micrometer-screw (D) which moves the plunger (E) projecting into the mercury-filled space, and thus causes the mercury column to move along the capillary tube.

[ThE I.MECH.E.] 3 × 2 
When the hollow cylinder is stressed perfectly axially, its volume decreases under compression and increases in tension, and by reason of this an amount of mercury equal to the volume change is forced into or withdrawn from the capillary tube. In the first case the expelled mercury which cannot remain in the capillary tube collects in the bulb (F) at the end of the tube, until, by turning the micrometer-screw, the end of the mercury column is brought back to the edge of the datum mark. Although the walls $(G)$ of the steel cylinder are thin in order to obtain large volume displincements of the mercury, which are thus readily observed, the box is so designed as not to be loaded above its elastic limit. It, therefore, shortens proportionately with the end loading and decreases in volume, consequently the amount by which the micrometer-screw has to be turned is also proportional to the load.

By reason of the fact that the micrometer reading is always got by returning the level of the mercury column to the zero mark, the number of turns given to the screw and the readings on the graduated scale are independent of the bore of the capillary tube. If a tube gets broken, it is, therefore, only necessary to replace it by another, without any fresh calibration of the instrument being necessary. Graduations are provided on the stem (H) to indicate the number of complete turns required to restore the mercury to the datum mark, and the edge of the screw is divided into 100 parts of about $1 \mathrm{~mm}$. length, so that hundredths of a turn may be casily read when the stem is brought into a suitable position, as is usually done in the preliminary setting.

The reverse action takes place when the box is subjected to tension, by using the tail pieces (l) which act in the sphericalseated screw-nuts $(J)$. The cylinder then stretches and its volume is increased. The level of the mercury column falls back into the box, and the plunger of the micrometer-screw must be advanced to force the mercury back to the zero mark. The tensile standardizing boxes shown in Fig. 2, Plate 14, are double-purpose instruments, and to convert them into compression calibrating buxes it is only necessary to take off the screw-nuts ( $J$, Fig. 1, Plate 14), and the tail-pieces (I). As a precaution to ensure that the 
testing-machine under trial should give a purely axial compression to these boxes, it is advisable to mount them on two end-pieces as shown in Fig 3, Plate 14. The bottom one is simply a hardened steel cylinder ground with perfectly smooth parallel faces, but the upper bolster is in the form of a spherical seating.

These boxes are comparatively light and very easily handled, and as the 30-ton size only weighs $20 \mathrm{lb}$, exclusive of the endpieces, they are much more convenient to use than dead weights, against which they are, of course, very carefully calibrated in the maker's works. Much patient and careful workmanship is necessary in the construction of these instruments out of the most carefully selected and perfectly heat-treated material; but as the result of their researches and experience Dr. Alfred J. Amsler and Co. are able commercially to produce perfectly reliable and constant reading instruments. As an example of the minuteness with which the calibration of these boxes is executed, Table 3 (page 954) is given to show how standardizing box No. 150 for 30 tons tension or compression loading has been experimentally dealt with, and the English values engraved on the micrometer-screw derived from the plotted values of the constants by interpolation.

To check the accuracy of a testing-machine of any kind, by means of this standardizing box, the Authors have found it advisable to get the highest consistency in their readings by leaving the instrument in the machine for several hours under a slight load. This effects the complete equalization of the temperature of the box and the machine, and the instrument is handled as little as possible during the test. The level of the mercury column is first brought to about the middle of the capillary tube, the micrometer-stem being turned into a suitable position for reading, and there secured by a lock-nut. Next, the sliding mark is brought to a point just beyond the mercury column with the slit in it facing the operator. A slight motion of the micrometer-screw brings the mercury exactly to the outer edge of the mark, and the first micrometer reading is taken. Now the load is applied uniformly, keeping the micrometer-screw turning so as to maintain the mercury column near the inner edge of the datum mark. When the desired load is 
attained and kept constant, the mercury Jevel is brought up exactly to the outer edge of the zero mark, and the second micrometer reading taken. The difference is the number of turns corresponding to the load applied. The load is finally released gently, keeping the micrometer-screw turning in the opposite way to retain the mercury in the capillary tube; then when, the load is completely off, the level is again adjusted to the outer edge of the mark and a third reading taken. If there has been no temperature change, the final reading agrees with the first, but, if not, then the slightly different reading is noted, and a mean is taken of the two differences observed. The experiment is repeated, using an increased loading right up to the maximum limit of the box, and comparison is made with the values engraved on the handle of the micrometer.

Application of Elastic Column Dynamometer to Hardness Testing.A new adaptation of this mercury-box load-measurer coupled with the micrometer-handle arrangement has recently been made by Dr. Alfred J. Amsler in connexion with a hand-operated screwpress with a maximum capacity of 5 tons (metric). Tests may be made with any form of this machine upon any material which does not fail or fracture under the load applied to it, such as, for example, in spring testing or in making hardness determinations of a metal, using either the Brinell ball or the Ludwik cone method.

In the new form of dynamometer fitted in the movable head-stock of the press, use is made of the principle of the elastic deformation of three sufliciently strong steel columns to measure the load applied to the test-piece. The small amount by which these columns shorten under load is magnified by means of a mercury box, so that the volume of mercury expelled into a capillary glass tube can be measured in the same way as in the standardizing box by rotating a micrometer-screw handle. This returns the mercury level to the original datum point, and the load reading is taken directly from the graduations on the handle of the micrometerscrew, as formerly explained, in the calibrating box.

The construction of this dynamometer is shown in section in Fig 4. The body consists of a hollow casting, the top shoulders (A) of 


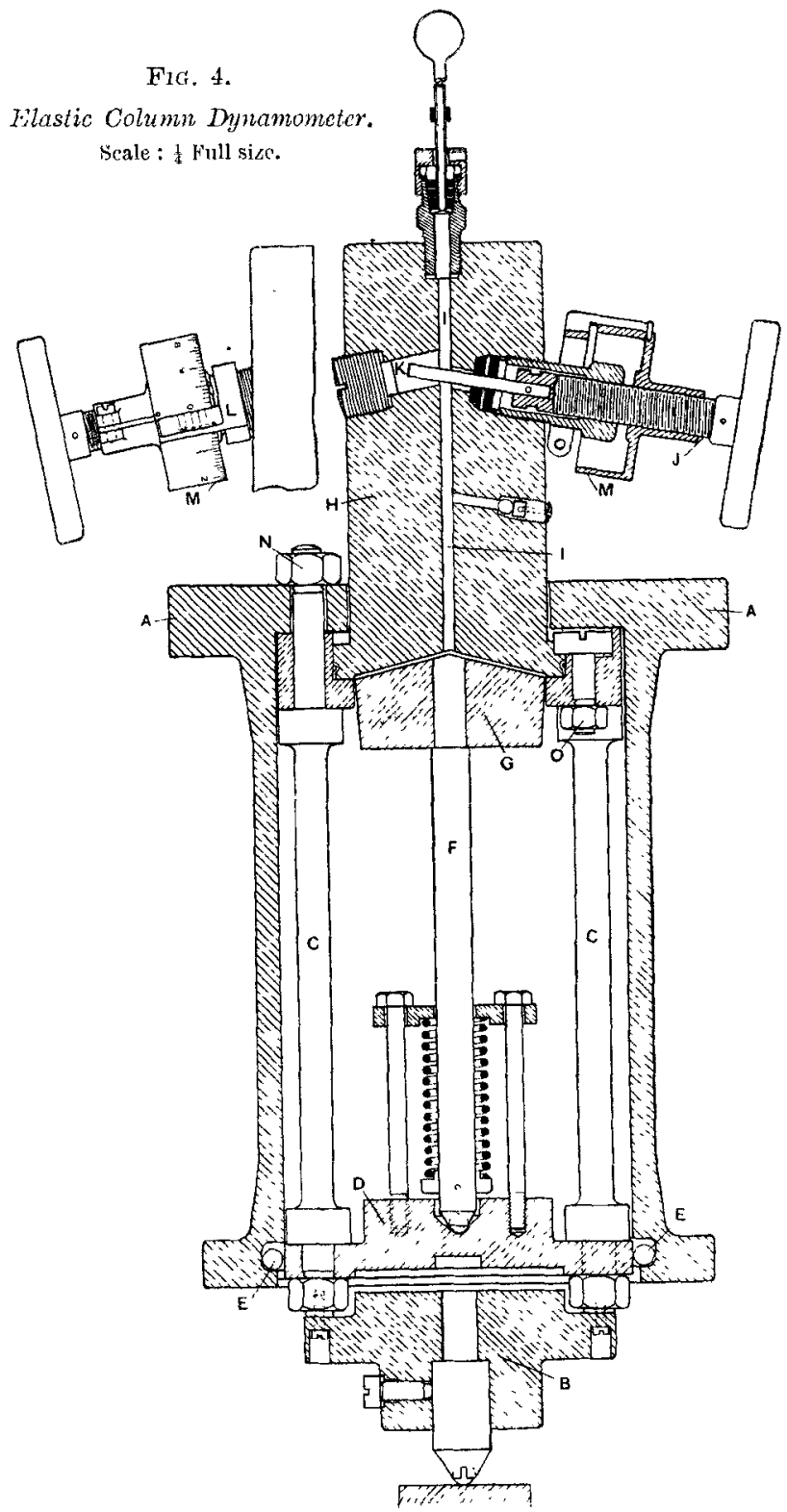


which are securely attached to the base of the press, not shown in this Fig. The compression plate (B) of the machine carries the indenting ball or cone, and is securely screwed to the lower ends of the elastic columns (C), and connects also with the yoke-plate (D), fitting loosely into the bottom of the dynamometer casing. This plate is able to move freely, being held in place by the balls (E), which are kept in their place in the groove by thick grease when the dynamometer is taken out of its casing. The load applied to the testpiece by the ball or cone is transmitted by the columns (C) to the shoulders (A), which provide the reaction. Under the compression load, the columns (C) shorten by a small amount, which is always proportional to the load they transmit, since they are designed to undergo no permanent deformation, thus acting as springs. The central column (F) is free to move so that it does not get stressed. It carries at the top end a piston $(G)$ which moves a short distance into the space filled with mercury between the piston and the steel cylinder $(H)$. The distance which the piston moves is equal to the amount by which the columns (C) become shortened, and as the tightness of the fit between the piston and the mercury space is ensured by a rubber membrane, the amount of mercury thus expelled into the capillary tube (I) is always proportional to the load applied to the compression plate (B), and thence to the specimen by the Brinell ball.

In order to measure the quantity of mercury expelled by the piston, use is made of the micrometer-screw $(J)$, the point of which (K) projects into the mercury. On turning this screw, the level of the mercury in the capillary tube can be adjusted to any height, this being always brought back to the fixed datum mark to take the readings on the micrometer-screw handle. The amount by which the handle of the screw is turned is the measure of the load applied, the dimensions of the plunger $(K)$ being such that one romplete turn, read on the scale (L), corresponds to $1,000 \mathrm{~kg}$. The scale on the drum (M) is divided into 100 parts, so that each part represents $10 \mathrm{~kg}$. Thousandths of a turn can be estimated, thus giving the load reading to the nearest kilogram. The drum $(M)$ is adjusted on the screw $(J)$ so that the micrometer reading is 
zero when there is no load on the press. The scale pointer $(L)$ is fixed to the screw-carrier so that it can be adjusted, and this enables the pointer to be fixed in a position where it can be conveniently read. The arrangement for reading the load is quite independent of the bore of the capillary glass tube, since the reading is only taken after bringing the level of the mercury column back to the upper edge of the datum mark. In consequence, if the capillary tube is accidentally broken, it only needs to be replaced by another without there being the slightest necessity for restandardizing the press. This form of dynamometer thus forms a very exact and sensitive measuring device, and yet it is at the same time very strong, being absolutely unbreakable at the maximum load which it is designed to measure. The only part which may deteriorate after a long period of use is the rubber membrane, and immediately this sheet gets torn the fact is known by some drops of mercury escaping through the bottom of the apparatus. In order to change the rubber sheet the screws which project from the steel cylinder (H) are removed, then the screwnuts $(\mathrm{N})$ are taken off the top of the shoulders (A) and the whole dynamometer arrangement can be taken out from the bottom. By unscrewing the nuts $(O)$ the cylinder $(H)$ is freed, so that a new rubber membrane is stretched over the end of the cylinder and fixed there by a wire in the groove. The complete arrangement is then reassembled in the reverse order from that in which it is taken to pieces.

Description of Screw-Press:-A general view of the arrangement of the 5-ton screw-press used for making hardness tests by means of the elastic column dynamometer is given in Fig 5, Plate 15, which shows the machine making a ball indentation on a steel cylinder set or the base of the press. The construction of this strongly built machine is shown in Fig 6, which illustrates how the movable head-stock carries the dywamometer, and also the micrometer measurer for load determinations, on the straining-screws anchored in the base plate of the machine. By turning the handle (A) of the machine the direct action of two worms on the spindle (B) causes 
the worm-wheels (C) to rotate on the right- and left-handed straining screws (D) so as to raise the head-stock quickly to admit a specimen up to 20 inches in height in the normal machine, or a wheel 6 feet high in the specially constructed presses. After the

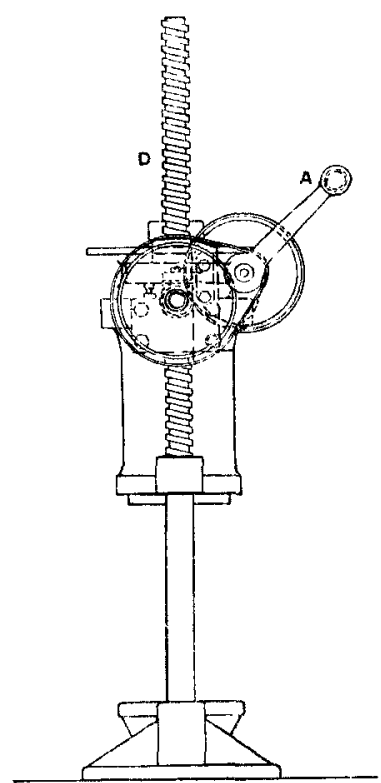

INS. 12

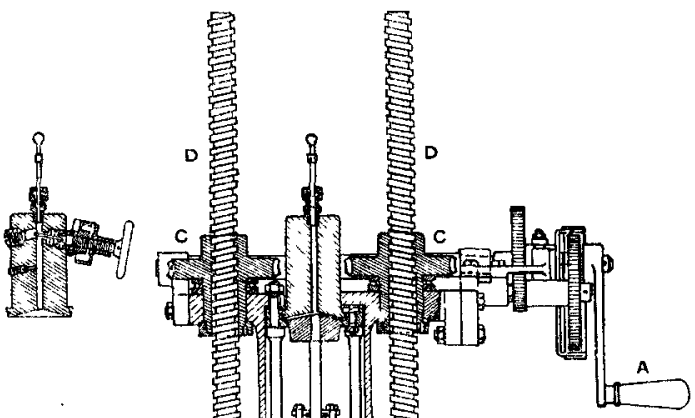

Fig. 6. - 5,000 Kg. Screw-Press for Hardness Tests with Ball or Cont.

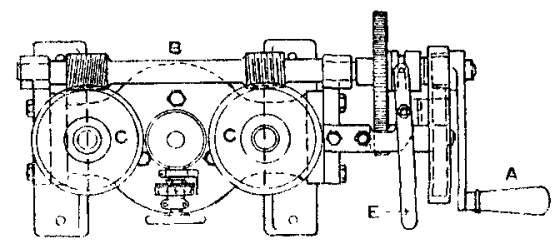

test-piece has been set level on the macline base, the handle is turned to bring down the ball or cone-carrying bolster at the bottom of the dynamometer attachment until it almost touches the metal surface to be indented. Then the slide-lever (E) is made to displace the spindle (B) axially so as to put in the reduction gearing and give the slow speed used for applying thelload. As the loading 
increases, the mercury column rises in the capillary tube above the position (about half-way up) where the datum mark has been fixed when the loading was zero and the micrometer reading was also nothing. As the right hand turns the press handle (A), the left hand can be used to rotate the micrometer-screw handle and thus maintain the level of the mercury column at or below the datum mark until the desired load is attained, when the mercury column is adjusted to coincide exactly with the top edge of the mark. Instead of this procedure, it is often preferable to set the micrometer-handle by three complete turns, thus corresponding to the $3,000 \mathrm{~kg}$. usually applied to a $10-\mathrm{mm}$. ball, and then each time the load is applied to a specimen the level of the mercury is raised by the pressure applied till it reaches the top of the zero indicator. If this method is followed, it is occasionally advisable to make a zero adjustment by moving the sliding datum mark in order to eliminate any error which might arise in consequence of a temperature change.

The desired load is maintained for a convenient period, say 15 or 30 seconds, and then the pressure is released by reversing the motion of the handlo. In this way a number of tests can be quickly made, different sizes of test-piece requiring the position of the head-stock to be adjusted by the quick motion of the wormwheels to attain a suitable initial position with the ball or cone just touching the smoothed surface of the specimen. The subsequent determination of the Brinell hardness in $\mathrm{kg}$. per $\mathrm{mm} .{ }^{2}$ may be done in the usual way of measuring the diameter of the imprint by a traversing screw microscope, or more conveniently by using a transparent celluloid taper-scale with the distance between the two divergent lines engraved in teuths of a millimetre on the underside next to the metal surface.

Lse of the Depth Indicator and Graphs..-One of the strongest objections which may be raised against the common method of getting the hardness value of a piece of metal by the measurement of the imprint diameter is that the raised ridge caused in a soft piece of metal gives too large a reading. This gives too great a value to the area of the impression and hence too small a value to 
the determined value of the hardness number. This is, of course, quite different from the low values got in excessively hard specimens due to the flattening of the ball under high pressures.

To obviate this serious objection, the Authors have found it extremely useful to employ a simple form of depth indicator, Fig. 7, Plate 15, for measuring the depth of the ball or cone imprint made in the test-piece whilst still in the machine. This little instrument

FIG. 8.-Depth Indicator (Amsler), reading to ${ }_{100}^{1}$ th $\mathrm{mm}$.

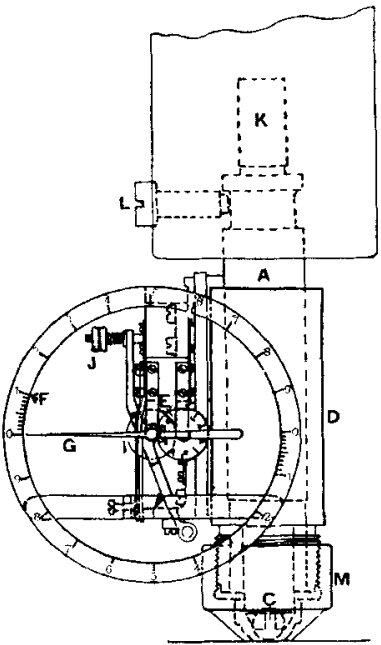

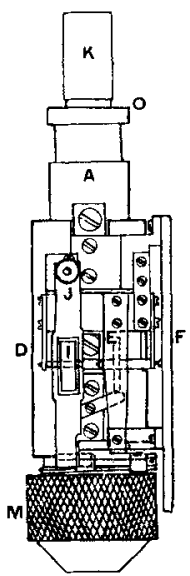

LuLLul

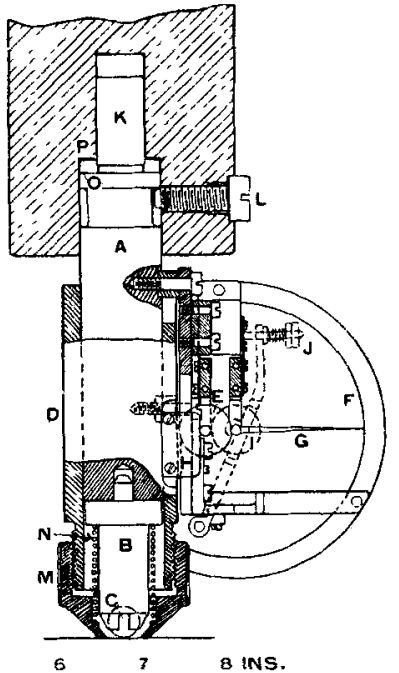

INS.

cun be attached to the compression plate of the press in the bottom of the dynamometer attachment where the ball or cone punch is usually placed. It consists of a bolster (A), see Fig. 8, at the end of which can be fixed a punch (B), provided either with a ball (C) or a cone. The bolster slides easily inside the sheath made in the form of a hollow cylinder (D) which rests by its own weight on the test-piece, and on which is mounted the amplifying arrangement for indicating the depth of the imprint to the nearest 10 th of a millimetre. During the test, the ball or cone fixed at the end of the bolster penetrates the test-piece due to the load applied to it, 
whilst the sheath of the instrument does not move with respect to the test-piece, so that the relative movement between the bolster and the sheath is exactly equal to the depth of the imprint produced.

The measurement of this depth to the nearest $\frac{1}{100}$ th of a millimetre is done by means of two graduated dials, the smaller of which (E) indicates whole millimetres, and the large dial (F) records in $T_{10}$ th of a millimetre The edge of the smaller dial is provided with very fine teeth which gear with a small wheel on the spindle of the pointer $(G)$, which makes a complete revolution before the large dial for a depth of imprint of 2 millimetres. The spindle of the small dial is given its motion by engaging with a hardened steel plate (H) fixed to the sheath, and the pressure between the plate and the spindle necessary to prevent any slipping between them is ensured by adjusting the outer rim of the small ball-bearing $(\mathrm{I})$ through screwing up a spring by the lock-nuts $(\mathrm{J})$.

In making a hardness test with the depth indicator, the instrument is first fixed in the compression plate by passing the tail-piece (K) into the recess in the plate, where it should slide without friction. The weight of the indicator is carried by the screw (L), which simply keeps the instrument from falling without fixing it. The outer sheath (D), with the screwed-on, knurled feeler (M) falls to the bottom of its travel, whilst the punch (B), with the ball (C), is held up, due to the pressure of the helical spring (N). The feeler (M) first comes in contact with the piece of metal to be tested, and this, along with the casing (D), is lifted up until the ball also comes into contact with the specimen. The exact instant that this happens is readily observed, for so long as the feeler rises with respect to the ball, the pointer (G) turns round the dial (F), but it stops immediately the ball comes in contact with the test-piece, for then the relative motion of the feeler and the ball ceases. The ball punch (B) is now raised, along with the feeler (M) and the whole body of the instrument, until the surface (O) of the bolster comes in contact with the surface (P) of the compression plate. Whilst the instrument is traversing this distance the pointer is not moving, and during this time it should 
be adjusted to point to one of the zero marks on the dial. This is very easily done by turning the feeler (M) round on the screw of the sheath. The desired load is then applied, and the pointer will traverse the graduated dial so long as the ball is being indented into the metal under test. If the reading were to be taken whilst the specimen was still subjected to the full load it would not be correct, on account of the small amount of elastic deformation of the specimen, the ball, and also the depth indicator itself. In order to obviate this inaccuracy, it is necessary to release the load on the ball to almost nothing, retaining only a few kilograms pressure to keep the ball perfectly in contact with the imprint, before taking the correct reading of the depth, from which the lindness value in kilograms per square millimotre can be calculated from the simple formula :- $-\mathrm{H}=\frac{\mathrm{P}}{\pi d t}$ where $(d)$ is the ball diameter and $(t)$ the depth of imprint in millimetres.

The hardness number obtained for a metal sample by using the depth of the imprint is always slightly different from that got by calculating from the measured diameter of the imprint. This difference is due in most cases to the raised ridge of metal produced round the imprint by the deformation of the test-piece. In measuring the diameter it is really the diameter of the raised ridge which is observed, whilst by measuring the depth of the imprint it. is only the effective distance which the ball has penetrated the metal that is taken as the basis of calculation. Another advantage of the depth indicator is that it enables observations to be made of the way in which the depth of imprint varies with the loading as the test proceeds. It can also be used to measure a definite depth of penetration which may be taken as a standard; the dynamometer of the screw-press is then used for determining the variable load required to produce this definite indentation. To save the awkward calculations which this method would entail, the Authors recommend the use of graphs prepared on logarithmically-squared paper, which reduces the parabolic curves got on ordinary squared paper to straight lines (as shown in Figs. 9, 10, and 11.)

'The standardizing of the elastic column dynamometer as mounted 
Fia. 9.-Brinell $10 \mathrm{~mm}$. Ball.

Tests made with Pressure os from 500 to $6,000 \mathrm{~kg}$.

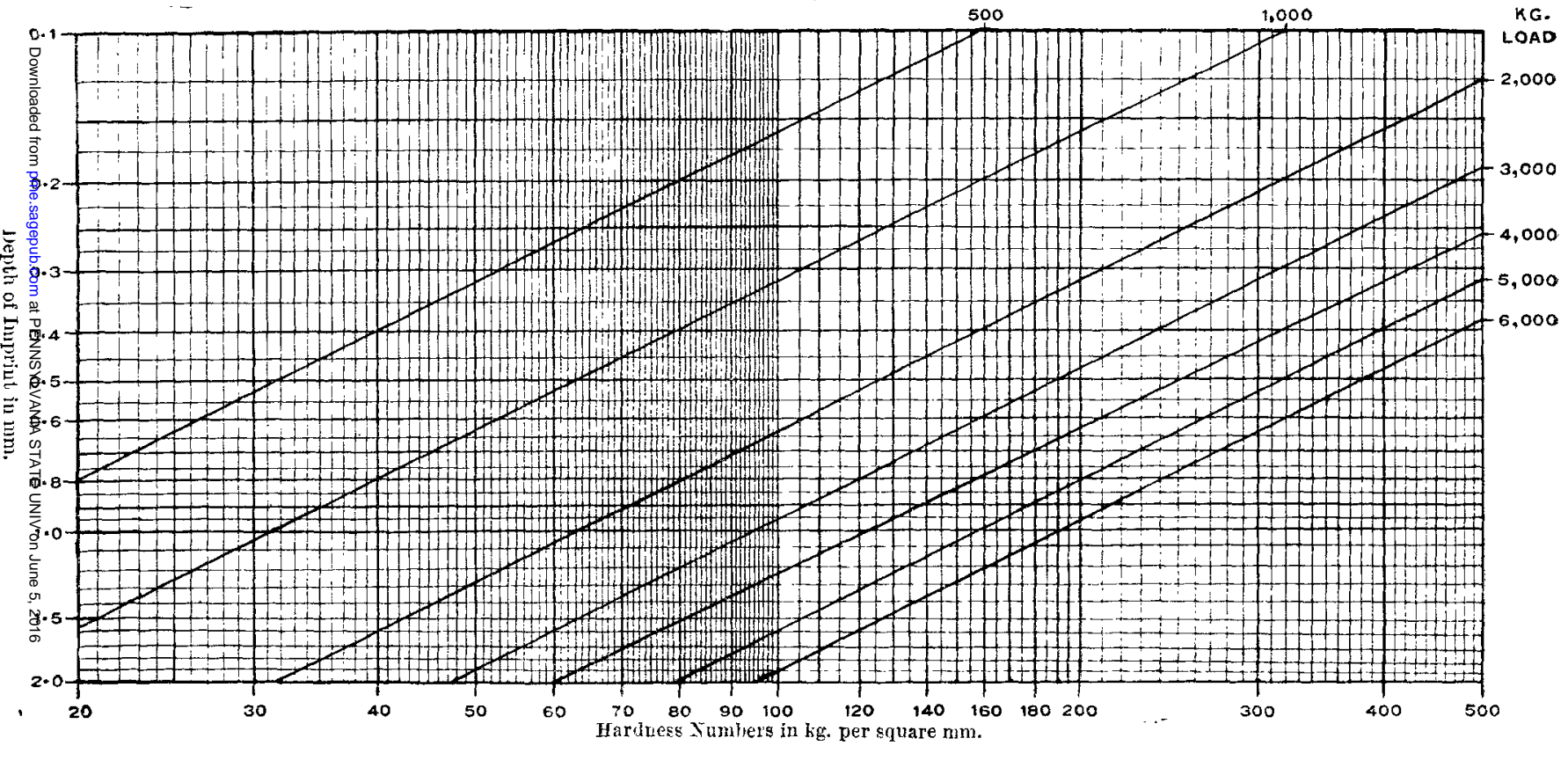


FIG. 10.-Ludwili $90^{\circ}$ Angle Cone.

Tests male with Pressures from 500 to $5,000 \mathrm{Kg}$.

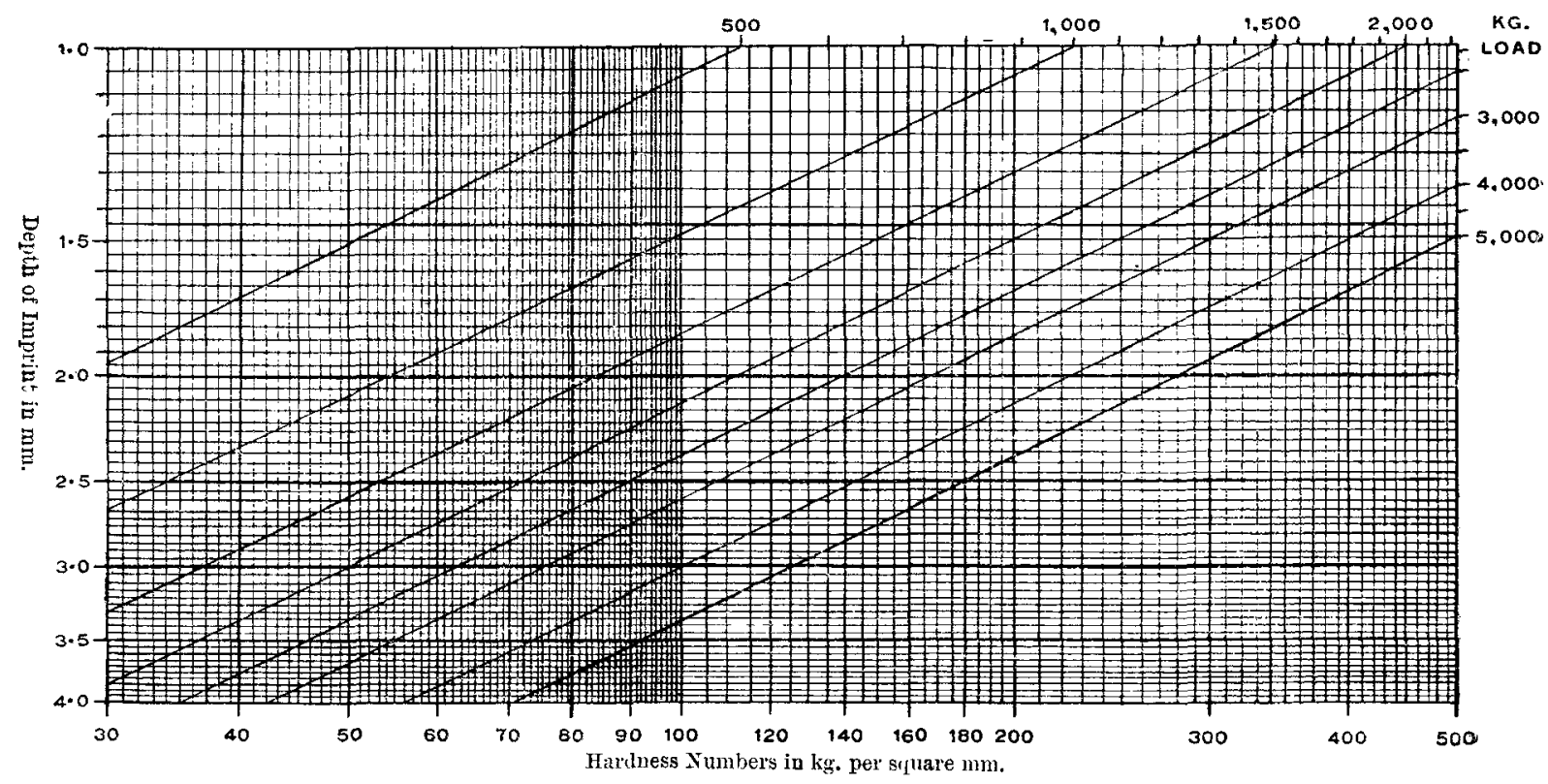


FIG. 11.-Brineli Hardness.

T'ests mude with $10 \mathrm{~mm}$. Ball and Pressures from 500 to 6,000 $\mathrm{Kg}$.

500

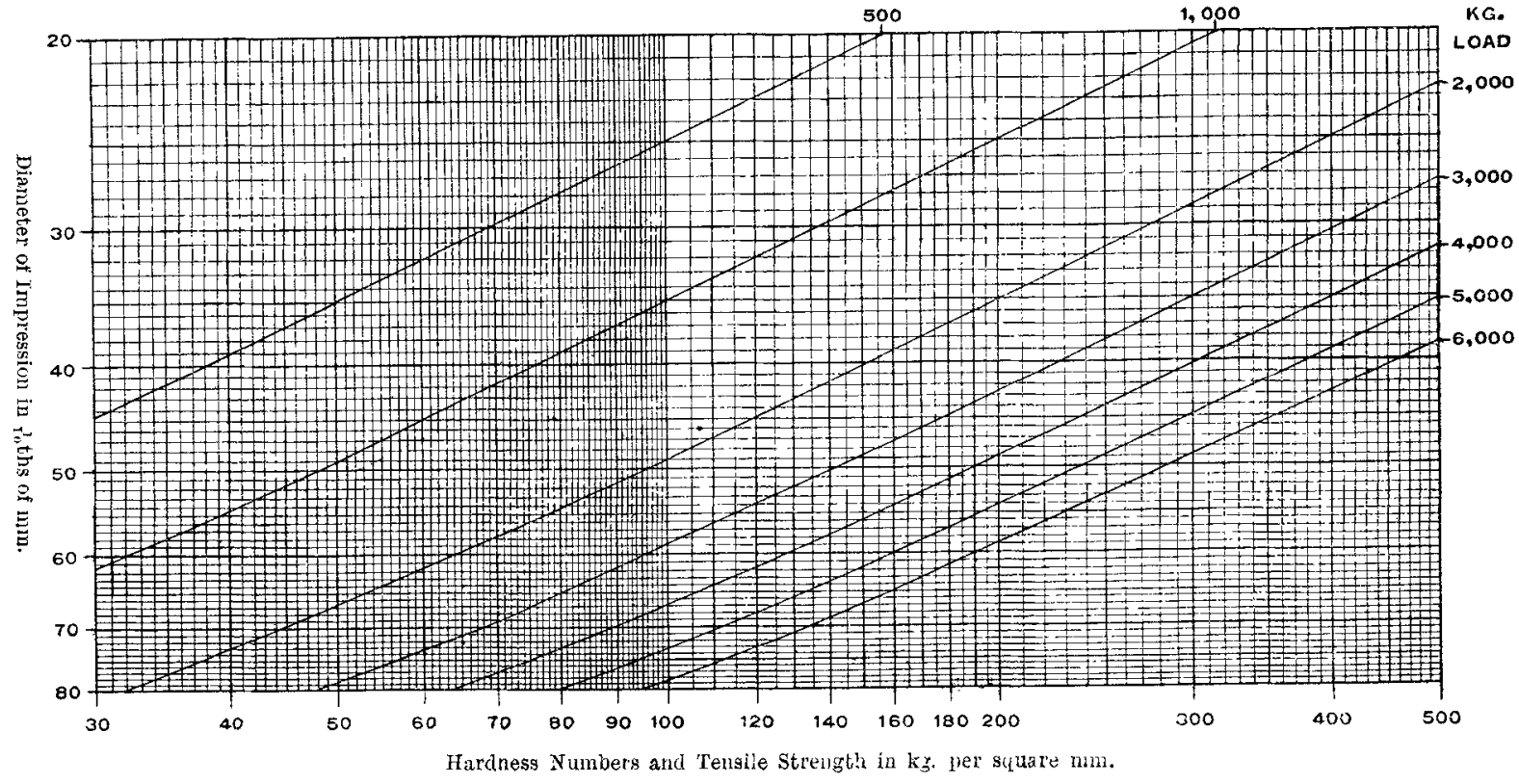


in the 5-ton press is very easily and simply accomplished. It is only necessary to hang the whole machine up by the compression plate in which the Brinell ball punch is mounted by using a suitably arranged cross-piece. The micrometer load indicator should then indicate exactly the net weight of the machine, about $300 \mathrm{lb}$., which may be easily determined beforehand by weighing it. Additional weights may then be placed on the machine base, or they may be suspended from the base by means of another cross-piece, and each new dead weight checked against the micrometer reading in kilograms.

Hardness Machine with Pendulum Dynomometer,-This machine combines into one complete outfit a depth indicator for accurately reading the depth of the ball or cone imprint made in a test-piece of metal by means of an oil-operated hydraulic press, the load indications of which can be varied in four degrees of sensitiveness up to 5 tons load, and the measurement of the loading applied is effected by means of a pendulum dynamometer. Fig. 12, Plate 15, illustrates the method of using the machine, which weighs $750 \mathrm{lb}$. It takes up a floor space of 2 feet by 1 foot, and is most conveniently set up on a table about 2 feet high so as to bring the two dials opposite the observer at a convenient height for easy reading. Details of the construction of this type of press on the well-known Amsler principle are given in the sectional drawings of Fig. 13, for the use of which the Authors have to thank Messrs. W. Reavell and Co., Ltd., Ipswich, one of the first users of this form of machine in this country.

The test-piece is set on the compression plate (A) resting in a spherical seating arranged on the top of the ram (B) of the oil press (C), the fitting of these two parts being sufficiently accurate to do away with the necessity for packing of any kind to ensure a suitable oil-tightness. A slight infiltration of oil between the ram and the cylinder walls enables the ram to be moved without friction, and a small tommy-bar enables the ram to be rotated by hand without any perceptible friction when the ram is not resting on the bottom of the cylinder, which must be assured before commencing a hardness test. 
Frg. 13.-5,000 Kg. Hardness Testing Machine. (Amsler).
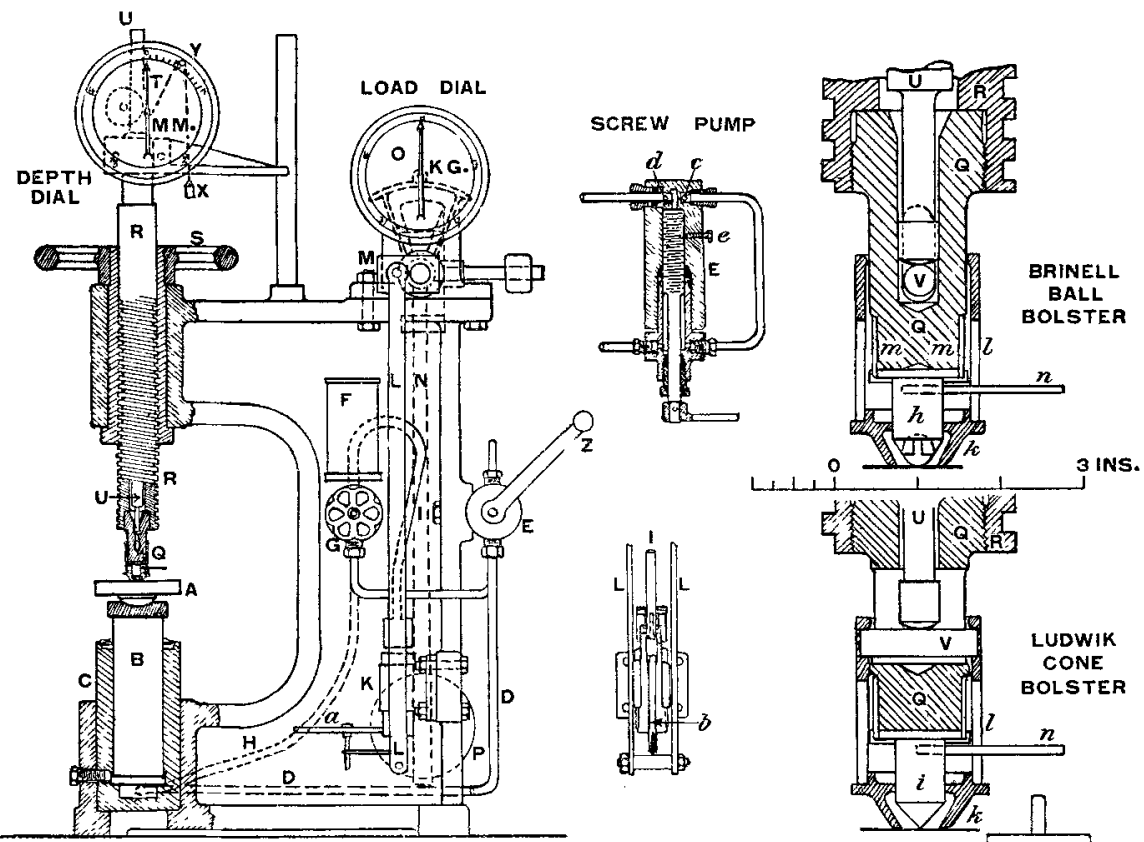

BALL
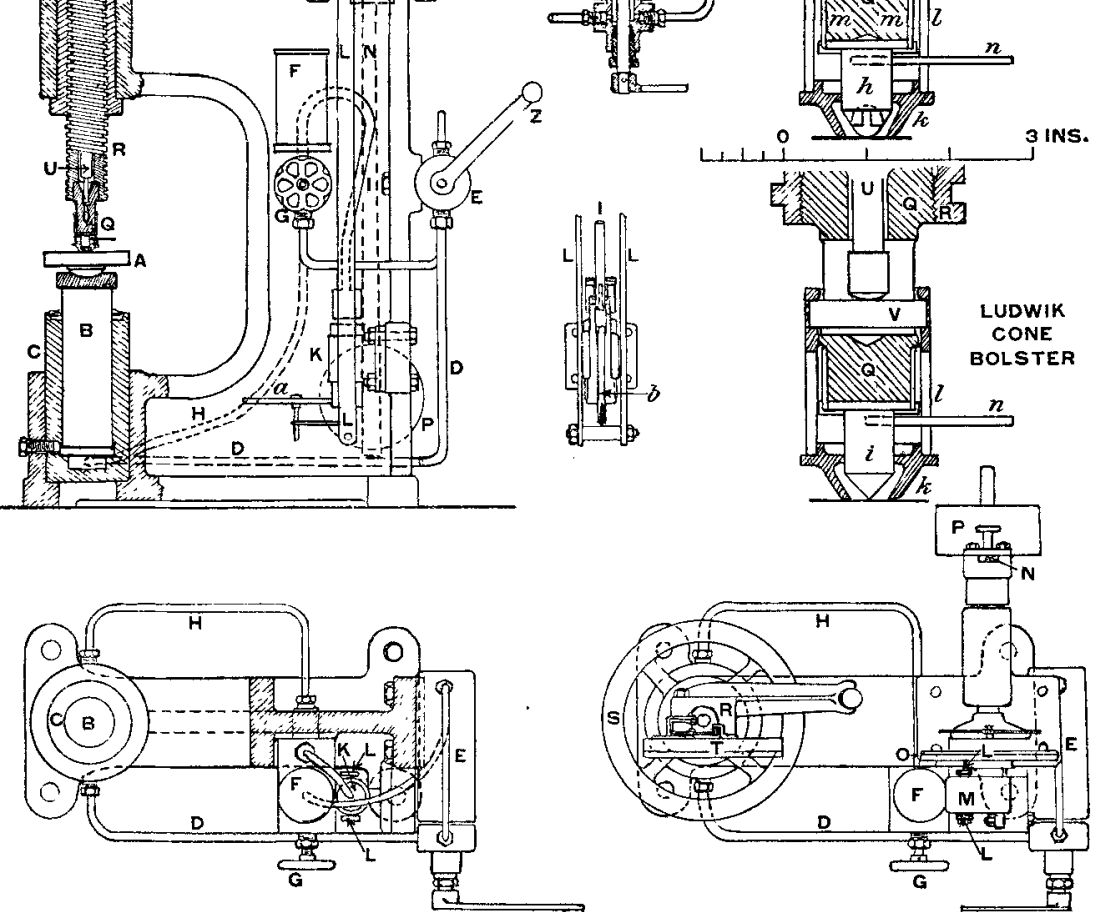

INS. 12

6

$2 \longdiv { 9 }$

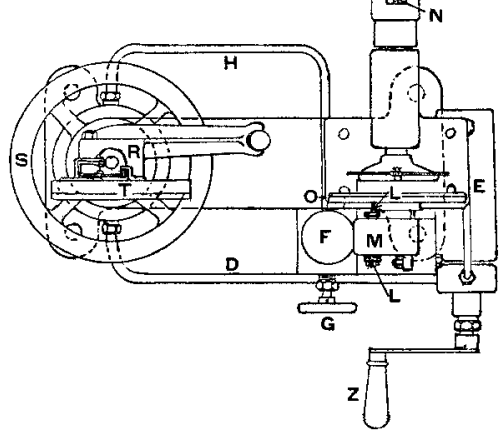


Oil under pressure enters the cylinder (C) from the pipe-line (D) leading from the pump body (E) mounted at the right-hand side of the machine frame. This screw-pump is operated by turning the handle $(Z)$ in either direction, the necessary supply of oil for which is drawn from the reservoir (F), which should be partly filled with heavy machine oil. During the test the release valve $(G)$ must be kept closed to prevent the pressure oil from returning by the pipe $(\mathrm{H})$ to the reservoir (F), but communication is always open from the pipe (H) to the pipe-line (I). This pipe (I) is securely coupled to the cylinder (K), which can, however, be oscillated by the short lever $(\alpha)$ so as to eliminate any possible friction between the walls of $(K)$ and the small piston $(b)$, the area of which bears a definite relationship to the area of the $\operatorname{ram}(B)$. As the load is gradually applied to the test-piece, the small piston $(b)$ tends to be expelled from the cylinder (K), and in doing so it carries down with it the stirrup connecting the two straps (L) at the bottom. These two rods (L) are connected at their top ends through tho lever block (M), which is rocked over, and thus rotates in its ball bearings the spindle of the pendulum (N) forming the dynamometer, either alone or when loaded with the bob-weight $(\mathrm{P})$. The displacement of the pendulum-rod $(N)$ from the vertical provides the reaction which constantly balances the pressure of oil on the small piston (b), and hence the load applied to the test-piece by the $\operatorname{ram}(B)$.

When there is no load applied, the pendulum-rod (N) hangs vertically, and the pointer of the load dial (O) being held merely by friction is adjusted to zero when the ram (B) of the press cylinder (C) is just slightly raised. As the pendulum-rod is swung slowly out of plumb in balancing the load, the geared rack behind the dial rotates the spindle of the pointer and causes the hand to indicate the load, which can be raised to the desired amount by continuing to rotate the pump handle.

The ball or cone used to make the hardness imprint is mounted in the clip (l) by means of a pin (V) passing through a slot in the bolster (Q), which is securely screwed home in the lower end of the screwed rod $(R)$ to effect a proper seating. This 
straining-rod $(R)$ can be raised or lowered quickly by turning the hand-wheel (S), which is not used for applying any of the load. At the top end of the screwed $\operatorname{rod}(R)$ is carried the depth indicator (U) which engages with the spindle of the pointer. which passes over the face of the depth-indicator dial, reading up to $5 \mathrm{~mm}$. and being graduated to show hundredths of a millimetre. As it is generally necessary to measure very small sizes of imprint depths, it is necessary to adjust the zero reading of the depth indicator very carefully while there is still no load acting on the test-piece. The surface $(m-m)$ where the bolster $(Q)$ touches the cone or ball punch must be quite free from oil, as this would be expelled under load and affect the depth reading.

To make this adjustment, the ball or cone is lowered at the end of the rod $(\mathrm{R})$ by turning the handle (S) until the ball or cone almost touches the surface of the metal to be tested. Then the handle of the pump is turned to bring them together very slowly. At the instant when the ball or conical point just touches the specimen it is possible to feel an appreciable resistance being set up to the easy motion of the oscillating pin $(n)$ inserted in the ball punch $(h)$ or the cone punch $(i)$. The raising of the specimen, set level on the platform (A) so that it does not rock, will have brought the feeler $(k)$ resting on the test-piece surface into the same alignment as the ball surface or cone point, and immediately the ball or cone cannot be rotated on the specimen by the pin $(n)$, then the milled head of the rod (U) is turned until the pointer of the dial (T) rests at zero. Then the $\operatorname{rod}(\mathrm{U})$ is pressed lightly to the right in order to ensure the least possible contact between the screw and the pinion, and this allows the rod (U) to move without appreciable resistance in a vertical direction. The weight $X$ stretches the cord passing over the pulley $Y$, and tends to turn the pointer counter-clockwise.

By continuing to turn the pump handle $(Z)$, first in one direction and then in the other, the ram (B) is raised, and the testpiece is pressed against the ball or the cone, the feeler remaining at rest on the surface, and thus setting up a relative movement with respect to the ball or cone which is indicated on the depth 
dial. When the needle of the dial $(0)$ points to the desired load, the lever $(a)$ being meantime slowly oscillated, the pressure is maintained for a definite period, say 15 seconds, then the valve $(G)$ is gently opened so that the ram (B) falls back by its own weight, forcing oil into the reservoir (F), and thus slowly decreasing the load. When the pointer of the dial (O) comes back nearly to zero, the pin $(n)$ is taken in the left hand, and the handle of the valve $(G)$ is operated by the right hand and kept open until the pin $(n)$ is just able to be moved, with greater difficulty than when starting the test, and then the valve $(G)$ is closed. A small load of several kilograms will still remain on the test-piece, and the depth reading is now made on the dial ( $\mathrm{T}$ ). If the reading of the imprint depth had been made whilst the impression was under the full load, the elastic deformation of the ball or cone, the bolster and the test-piece itself would have falsified the reading somewhat.

The sensitiveness of the dynamometer can instantly be changed from one degree to another simply by changing the point of suspension of the pendulum-rod $(\mathrm{N})$. Four holes are found drilled in the rod $(N)$ and marked with the numbers, $500,1,000,2,500$ and 5,000 , which represent the maximum load in kilos which can be attained when the pendulun is suspended by the pin passing through one of the holes into the guiding stirrup, and the pointer makes a complete revolution over the load dial (O). For the two lower loads the pendulum-bob is taken off, but for the two higher values it must be attached to the sliding-pin at the bottom of the pendulum-rod. Four graduated scales are attached by screws to the dial-plate $(0)$, and care must be taken to read on the proper scale corresponding to the degree of sensitiveness selected for a particular hole by which to suspend the pendulum.

This machine is very rigidly and strongly constructed, and yet possesses a high degree of sensitiveness and accuracy. Both the ram (B) and the small piston (b) move quite freely when the ram is not at the bottom of the cylinder. The pendulum also swings quite freely when the straps (L) are raised from contact with the small piston (b). If, by any entry of air into the pipe-lines, the pump does not act, by simply loosening the screw (e) in the pump body 
and turning the handle in a clockwise direction the air is expelled, and the screw is tightened up again. If by mischance any impurities are admitted by the heavy oil, these may prevent the ball valves $(c)$ and $(d)$ from resting properly on their seats, when they must be removed and cleaned as well as their seatings.

Results. - In conclusion some Tables are given to show the comparison between the hardness values obtained with several steel specimens tested by the different methods mentioned in the Paper.

\section{TABLE 1.}

Brinell Hardness with $10 \mathrm{~mm}$. ball and $3,000 \mathrm{~kg}$. load.

\begin{tabular}{|c|c|c|c|}
\hline $\begin{array}{c}\text { Quality of } \\
\text { Steel. }\end{array}$ & $\begin{array}{c}\text { From Diameter } \\
\text { of Imprint. }\end{array}$ & $\begin{array}{c}\text { From Depth of } \\
\text { Imprint. }\end{array}$ & $\begin{array}{c}\text { Average Increase } \\
\text { due to Depth } \\
\text { Reading. }\end{array}$ \\
\hline B & $121-126$ & $127-136$ & 8 \\
C & $149-156$ & $159-166$ & 10 \\
D & $187-197$ & $191-203$ & 5 \\
\hline
\end{tabular}

\section{TABLE 2.}

Brinell Ball and Ludwik Cone Hardness tested on same specimen with different loads and methods of measuring imprint size.

\begin{tabular}{|c|c|c|c|c|c|c|}
\hline $\begin{array}{c}\text { Three } \\
\text { Imprints } \\
\text { made by: }\end{array}$ & \multicolumn{2}{|c|}{ From Depth of Imprint at } & Average. & $\begin{array}{c}\text { From } \\
\text { Diameter } \\
\text { at 3,000 } \\
\mathrm{kg} .\end{array}$ & $\begin{array}{c}\text { Average } \\
\text { difference. }\end{array}$ \\
\hline Ball & 132 & 138 & 136 & 135 & 126 & 9 \\
Cone & 133 & 132 & 134 & 138 & 122 & 11 \\
\hline
\end{tabular}


TABLE 3.

Schedule of Experimental Calibration of Amsler Standardizing

Box No. 150, for 30 tons tension and compression loads.

Experimental Determinations.

\begin{tabular}{|c|c|c||c|c|c|}
\hline \multicolumn{3}{|c||}{ Tension. } & \multicolumn{3}{c|}{ Compression. } \\
\hline $\begin{array}{c}\text { Toads in } \\
\text { metric } \\
\text { tons. }\end{array}$ & $\begin{array}{c}\text { Readings. } \\
\text { (Turns.) }\end{array}$ & $\begin{array}{c}\text { Ratio, } \\
\text { Reading } \\
\text { - Load. }\end{array}$ & $\begin{array}{c}\text { Loads in } \\
\text { metric } \\
\text { tons. }\end{array}$ & $\begin{array}{c}\text { Readings. } \\
\text { (Turns.) }\end{array}$ & $\begin{array}{c}\text { Ratio, } \\
\text { Reading } \\
\text { - Load. }\end{array}$ \\
\hline 25.9 & 8.405 & 0.3245 & $26 \cdot 1$ & 8.322 & 0.3189 \\
20.3 & 6.580 & 0.3241 & 20.5 & 6.561 & 0.3201 \\
14.7 & 4.750 & 0.3231 & 14.9 & 4.784 & 0.3211 \\
9.1 & 2.927 & 0.3217 & 9.3 & 2.984 & 0.3209 \\
3.5 & 1.122 & 0.3207 & 3.7 & 1.195 & 0.3230 \\
0.7 & 0.225 & 0.3214 & 0.9 & 0.290 & 0.3226 \\
6.3 & 2.020 & 0.3206 & 6.5 & 2.092 & 0.3219 \\
11.9 & 3.835 & 0.3223 & 19.1 & 3.882 & 0.3208 \\
17.5 & 5.665 & 0.3237 & 17.7 & 5.667 & 0.3202 \\
23.1. & 7.496 & 0.3245 & 23.3 & 7.439 & 0.3193 \\
25.9 & 8.411 & 0.3247 & 26.1 & 8.319 & 0.3187 \\
\hline
\end{tabular}

Interpolated Valitis.

\begin{tabular}{|c|c|c|c|c|c|c|}
\hline \multicolumn{4}{|c|}{ T'ension. } & \multicolumn{3}{|c|}{ Compression. } \\
\hline \multirow{2}{*}{$\begin{array}{l}\text { Loads in } \\
\text { tons. }\end{array}$} & \multirow{2}{*}{$\begin{array}{l}\text { Inter- } \\
\text { polated } \\
\text { Ratio, } \\
\text { Reading } \\
\text { - Ioad. }\end{array}$} & \multicolumn{2}{|c|}{$\begin{array}{l}\text { Evaluated Constants. } \\
\text { Turns for }\end{array}$} & \multirow{2}{*}{$\begin{array}{l}\text { Inter- } \\
\text { polated } \\
\text { Ratio, } \\
\text { Reading } \\
\text { - Load. }\end{array}$} & \multicolumn{2}{|c|}{$\begin{array}{c}\text { Evaluated Constants. } \\
\text { Turns for }\end{array}$} \\
\hline & & $\begin{array}{l}\text { Metric } \\
\text { tons. }\end{array}$ & $\begin{array}{l}\text { English } \\
\text { tons. }\end{array}$ & & $\begin{array}{l}\text { Metric } \\
\text { tons. }\end{array}$ & $\begin{array}{l}\text { English } \\
\text { tons. }\end{array}$ \\
\hline 5 & 0.32105 & $1 \cdot 605$ & $1 \cdot 631$ & 0.3221 & $1 \cdot 611$ & $1 \cdot 637$ \\
\hline 10 & 0.32220 & $3 \cdot 222$ & $3 \cdot 274$ & 0.3214 & $3 \cdot 214$ & $3 \cdot 266$ \\
\hline 15 & 0.32320 & $4 \cdot 848$ & $4 \cdot 926$ & 0.32065 & $4 \cdot 810$ & $4 \cdot 887$ \\
\hline 20 & 0.32405 & $6 \cdot 481$ & $6 \cdot 585$ & 0.3199 & $6 \cdot 100$ & $6 \cdot 503$ \\
\hline 25 & 0.32475 & $8 \cdot 119$ & $8 \cdot 249$ & 0.3191 & $7 \cdot 977$ & $8 \cdot 105$ \\
\hline 30 & 0.32540 & $9 \cdot 762$ & $9 \cdot 919$ & 0.3183 & 9.549 & $9 \cdot 702$ \\
\hline
\end{tabular}

The Paper is illustrated by Plates 14 and 15 and 7 . Figs. in the letterpress. 
Fig. 3.

Double purpose Standardizing Box arranged for Compression Test.

Fig. 1.

Section of

Standardizing

Box

(Amsler).

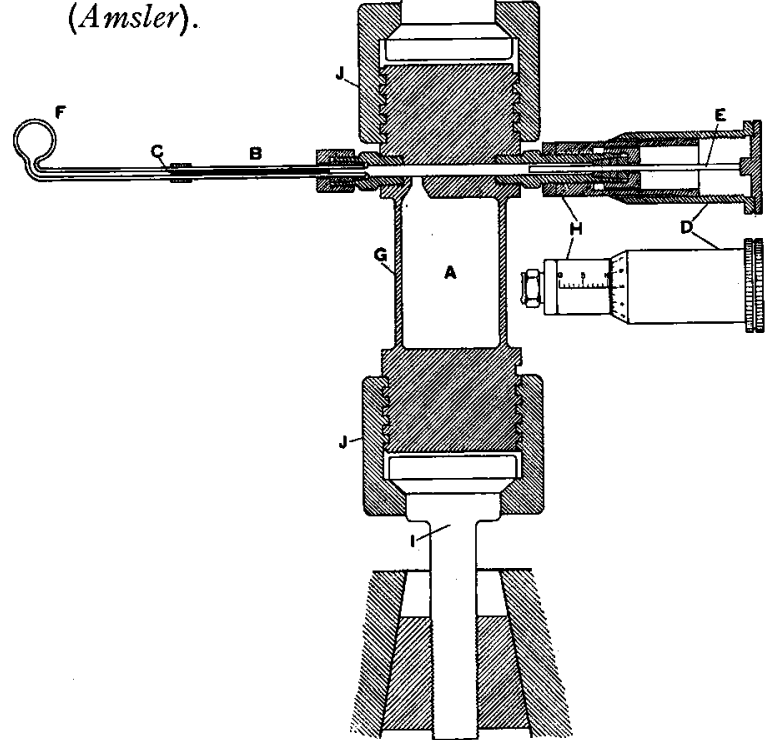

Fig. 2. 30-ton Standardizing Box in Tensile Testing Machine.

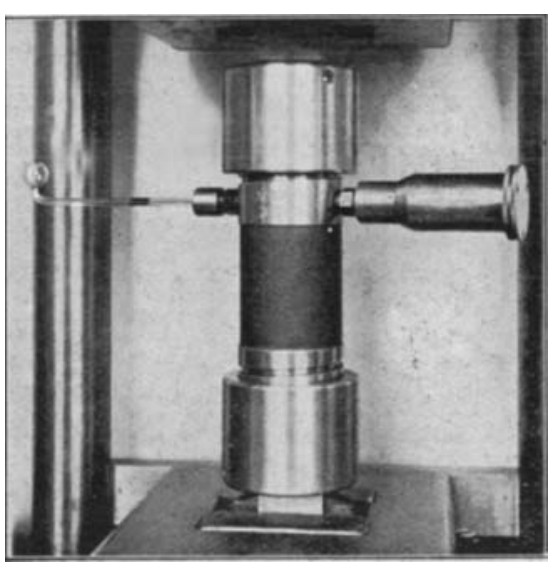

Mechanical Engineers 1920

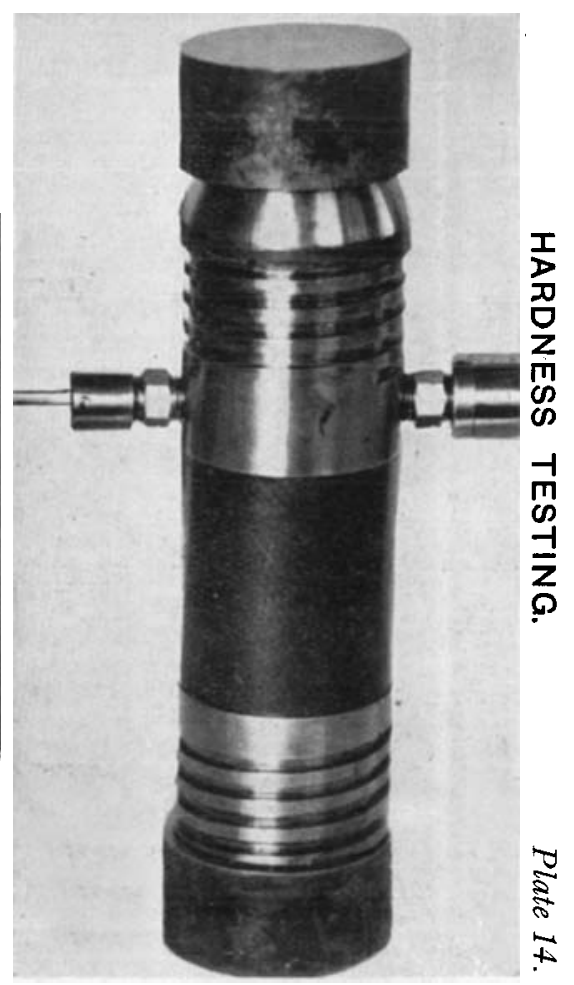


Fig. 5. 5,000 Kg. Screw-Press with Elastic Column Dynamometer for Hardness Tests.

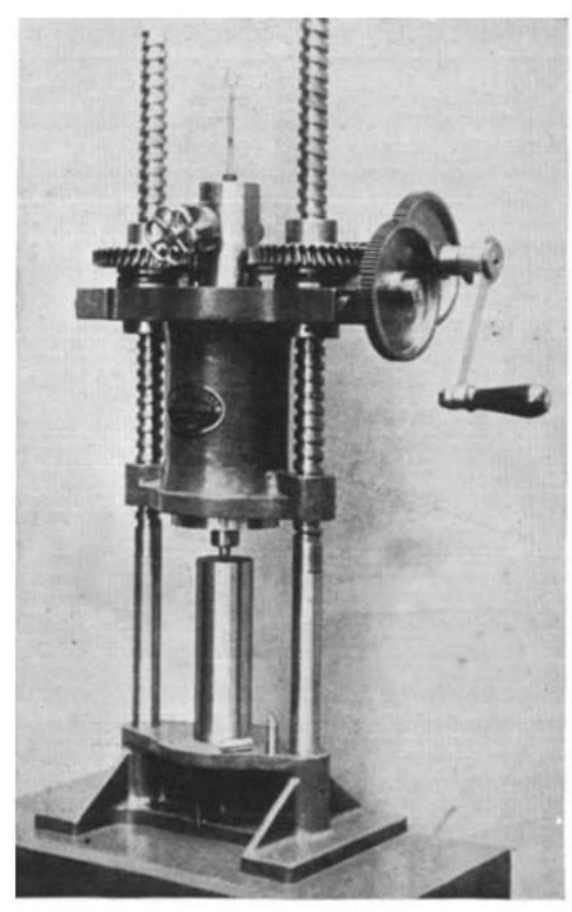

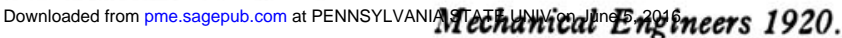

Depth Indicator

(Amsler)

for Hardness Tests.

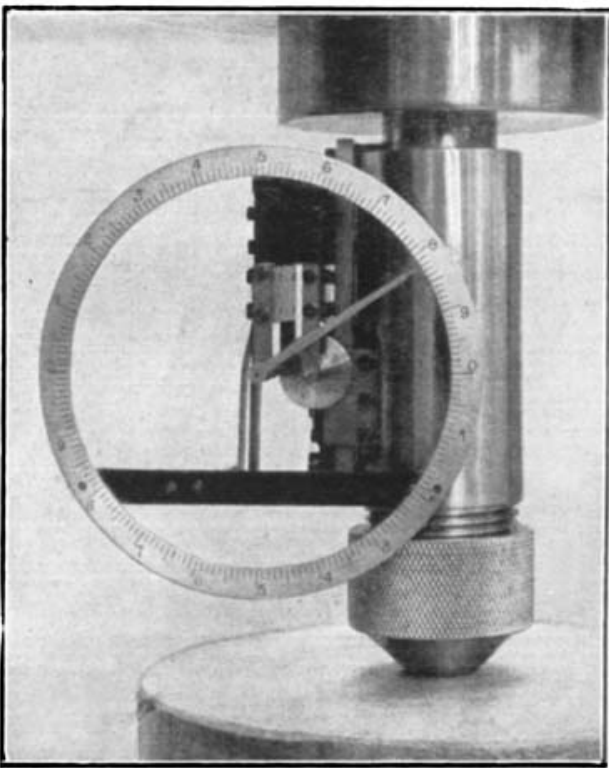

Fig. 12. 5,000 Kg. Hydraulic Press with Pendulum Dynamometer for Hardness Tests.

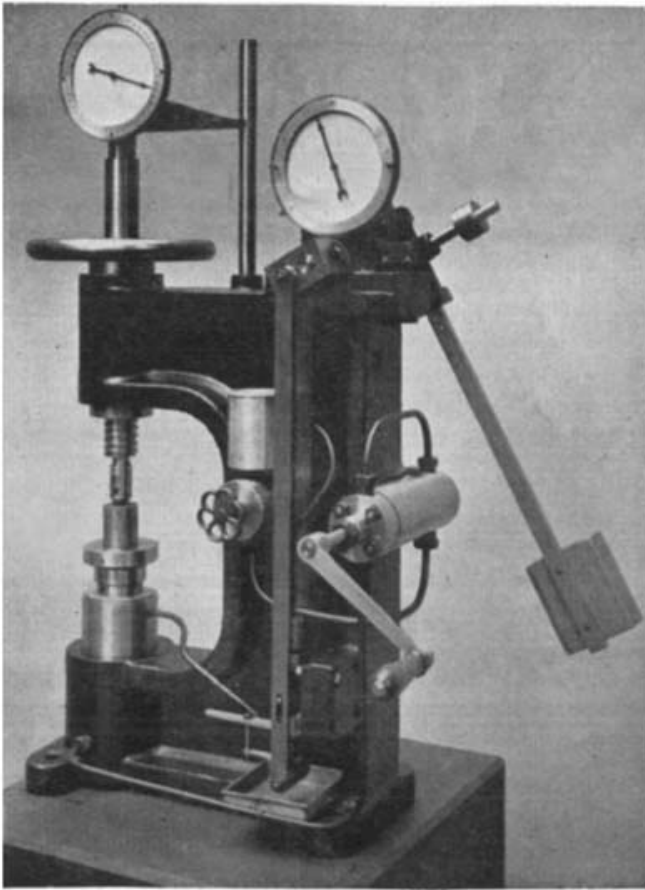

